\title{
Verdade e Justiça entre Oposição e Complementariedade: apontamentos sobre as diferenças no tratamento da Operação Condor pela Justiça de Transição no Brasil e na Argentina
}

\author{
Vanuza Nunes Pereira \\ Universidade Federal de Minas Gerais
}

\section{Introdução}

Os processos transicionais dos países sul-americanos têm sido alvo de uma frequente comparação, principalmente na busca de similaridades e distinções que possam explicitar e possibilitar a melhor compreensão das singularidades de cada processo, bem como a influência dessas particularidades nas transições para democracias, marcadas por rupturas e continuidades com os regimes autoritários.

Nesse sentido, a partir de um estudo de caso das ditaduras militares do Brasil e da Argentina, o presente trabalho tem o intuito de desvelar as práticas de "encapsulamento" das burocracias diplomáticas dos dois países durante os governos autoritários. A análise dos aparatos diplomáticos nessa quadra histórica - notadamente o Ministério das Relações Exteriores, em função de ser uma das instituições estatais de maior prestígio dentro do Poder Executivo Federal - tem a função de revelar questões centrais sobre as ditaduras militares sul-americanas, a exemplo da cooperação internacional e regional no combate aos considerados inimigos dos Estados, além de lançar luz acerca da relação entre o Executivo e a burocracia estatal preexistente.

A manutenção de quadros civis na burocracia diplomática brasileira e a insistência no discurso da neutralidade técnica do Ministério, ao passo que se dava a institucionalização de expedientes autoritários no cotidiano desses órgãos burocráticos, auxiliaram na construção de uma aparência de normalidade e legitimidade dos governos militares. Noutro sentido, as distinções dos processos transicionais, por sua vez, influenciaram os marcos interpretativos sobre o passado recente desses países, tendendo a ocultar ou revelar a cooperação dessas instâncias burocráticas com os seus respectivos regimes.

Para demonstração de nossos argumentos, optamos pela escolha de um fenômeno que teve características equiparadas para as atividades das burocracias diplomáticas, no caso, ações reconhecidas como transnacionais, portanto, celebradas além dos limites dos territórios nacionais e em cooperação com outros Estados: a Operação Condor. Trataremos sobre o caso de três argentinos desaparecidos no Brasil no âmbito da Operação, a partir das atividades desempenhadas pelas burocracias diplomáticas dos dois países e as distinções atuais no que tange a responsabilização judicial de agentes perpetradores de direitos humanos.

\section{Verdade e justiça entre oposição e complementariedade}

Protagonista global na luta pelos direitos humanos, a Argentina deu mais um passo à frente na consolidação de sua transição para o regime democrático (Sikkink, 2008). Recentemente, em 27 de maio de 2016, o Tribunal Oral Número 1 (n. 1), em Buenos Aires, depois de três anos de julgamento, 
reconheceu a existência e as ações repressivas conduzidas por uma organização regional ilícita, conhecida como Operação Condor ou Plano Condor, e condenou alguns dos envolvidos.

A Operação Condor é identificada como uma rede transnacional, um sistema secreto de ações e informações, instituída entre as ditaduras militares do Cone Sul da América do Sul - Argentina, Bolívia, Brasil, Chile, Paraguai e Uruguai. Suas ações constituíam-se e imiscuíam-se entre trocas de informações, espionagem, prisões, torturas, interrogatórios, intercâmbios e eliminação de pessoas, realizadas no âmbito dos países participantes ou ainda em territórios além da América Latina (Mcsherry, 2005). Segundo o pesquisador John Dinges (2005), “[n]a linguagem da segurança da América Latina em meados da década de 70, operação era a palavra usada para sequestro, interrogatório sob tortura e extermínio".

Entre 1975 e 1981, a Operação Condor é conduzida por um objetivo comum, o combate à "subversão", ou seja, a todos os indivíduos considerados contrários aos regimes ditatoriais impostos naqueles países. O dispositivo foi responsável pelo desaparecimento, tortura e assassinato de centenas de refugiados, militantes e líderes políticos. De acordo com relatório sobre o assunto, compilado pela Organização das Nações Unidas para Educação, Ciência e Cultura (UNESCO) em 2016, estima-se que houve cerca de 380 vítimas da coordenação repressiva, entre 1974 e 1981 (Garzón Real, 2016).

A investigação que culminou nas condenações por violações de direitos humanos numa perspectiva transfronteiriça, coordenada e operacionalizada pelos aparelhos estatais de regimes autoritários, ocorrido no Tribunal argentino, foi dividida em duas partes. A primeira tratou da Operação Condor e, a segunda, de crimes cometidos no centro clandestino de detenção, conhecido como Automotores Orletti, localizado em Buenos Aires. No total, 174 vítimas foram identificadas: 107 são vítimas da Operação Condor, 65 correspondem ao caso Automotores Orletti e duas são provocadas pelas duas causas. Os casos pesquisados para o julgamento mencionaram vítimas advindas dos países que integraram a Operação Condor - Argentina, Bolívia, Chile, Paraguai, Peru e Uruguai - exceto o Brasil (Procuradoria de Crimes contra a Humanidade, 2015).

Tais apontamentos, sobretudo que se refere à Operação Condor, encontram-se no Relatório da Procuradoria de Crimes contra a Humanidade, do Ministério Público (Fiscalía) da Argentina, que se debruçou sobre os casos de privação ilegal de liberdade agravada, perpetrada, total ou parcialmente, no território argentino, por funcionários públicos - civis, militares e/ou membros das forças de segurança - de qualquer dos Estados do Cone Sul. Investigou-se, principalmente, a participação dos membros das Forças Armadas da Argentina e do Uruguai no contexto da coordenação repressiva dos serviços militares, de segurança, diplomáticos e de inteligência na região.

O processo sobre a Operação Condor levou 17 anos, entre a propositura da ação, em 1999, e o julgamento final de 2016. Segundo a organização argentina de direitos humanos, Centro de Estudios Legales y Sociales (CELS), foram ouvidas mais de 200 testemunhas dos países envolvidos, além de 25 pessoas acusadas. Na sentença histórica, das 17 pessoas indiciadas, 15 foram condenadas por delito de associação ilícita ${ }^{1}$.

Segundo a pesquisadora Francesca Lessa (2016), uma seção do caso Condor continua na fase de investigação na Argentina, a cargo do Tribunal Penal e Penitenciário Federal $n^{\circ} 7$ e do Ministério Público Nacional (Físcalia) para Crimes Penais e Correcionais $\mathrm{n}^{\mathrm{o}} 10$ da Capital Federal. O universo

\footnotetext{
${ }^{1}$ Reynaldo Benito Bignone, o último ditador da Argentina, e o ex-comandante Santiago Omar Riveros estão entre os condenados. Além dos argentinos, o ex-militar uruguaio, Manuel Cordero Piacentini, também foi condenado por sequestros de uruguaios em Buenos Aires, ocorridos em 1976 (Lessa, 2016, p. 6).
} 
dos casos, incluindo os casos do julgamento e as novas investigações, engloba vítimas da Argentina, Bolívia, Chile, Paraguai, Peru e Uruguai e incorpora cidadãos do Brasil, da Alemanha e da Espanha (Procuradoria de Crimes contra a Humanidade, 2015).

O fato de que, no julgamento argentino, mais uma vez não terem sido apreciadas as responsabilidades dos agentes do Estado brasileiro envolvidos em violações a direitos humanos durante o regime militar - muito em função da anistia que ainda vigora no país - tem, por consequência, levar a sociedade civil, e/ou indivíduos diretamente interessados nas questões a procurar Tribunais internacionais em busca de reparação.

As graves violações de direitos humanos cometidas no marco da Operação Condor envolvendo o Brasil foram objeto de condenações da Corte Interamericana de Direitos Humanos em sentenças de mérito em pelo menos dois outros casos: Goiburú y otros vs. Paraguay, de 2006, e Gelman vs. Uruguay, de 2011. Nas duas ocasiões, a Corte Interamericana de Direitos Humanos estabeleceu que os serviços de informação de vários países do Cone Sul, entre eles o Brasil, formaram, no continente americano, durante a década de 1970, uma organização interestatal complexamente articulada com finalidades criminosas, cujo conteúdo continua sendo revelado ainda na atualidade.

O julgamento e, principalmente, a responsabilização de agentes dos aparatos estatais envolvidos com as atividades da Operação Condor na Argentina representam importante avanço no processo de revisão do passado, apontando para um novo paradigma na imputação dos agentes e aparelhos estatais de repressão. Com efeito, a judicialização de uma operação transnacional ilícita, coordenada por Estados ditatoriais em que, entre os partícipes, um deles reconhece oficialmente a ilegalidade institucionalizada daquelas ações, teve um significado emblemático no cenário nacional e internacional. Criou-se, a partir deste evento, um precedente importante para que outras atividades ilegais conduzidas por aparelhos burocráticos repressivos pudessem ser igualmente questionadas em juízo.

No contexto da proteção dos direitos humanos, o direito de saber é forjado de acordo com a percepção de que, com a ocorrência de graves violações de direitos humanos, muitas vezes em um período de violência extraordinária, praticada de maneira velada e sobre as quais não há documentação suficientemente publicizada, o tratamento desses direitos requer mecanismos específicos. Assim, nas últimas décadas, cientistas políticos e juristas debruçaram-se sobre o problema das medidas apropriadas para fazer frente a acontecimentos dessa ordem, desenvolvendo reflexões que vieram a integrar o campo de estudo e prática ao qual se deu o nome de justiça de transição.

Dentre o conjunto de medidas e mecanismos estabelecidos pela justiça de transição se destacam: direito à memória e à verdade; reformas institucionais (expurgos no serviço público); reparações às vítimas e justiça/responsabilização criminal (por exemplo, os julgamentos individuais por crimes contra a humanidade cometidos no período autoritário) (ONU, 2004). Paul Van Zyl (2009) acrescenta, ainda, o mecanismo da reconciliação às demais ferramentas da justiça de transição (Zyl, 2009).

Assim, a partir da interpretação de que a memória política e a justiça estão em constante processo de construção por meio de lutas sociais, jurídicas e políticas, é razoável sustentar que a ocorrência de um julgamento na Argentina, em que se avaliou a culpabilidade de agentes estatais pela participação em atividades ilícitas transnacionais, é resultado, ainda que secundário, da efetivação de outros direitos basilares da justiça de transição. 
Notadamente, a garantia do direito à verdade, consubstanciado na possibilidade de saber, esclarecer e revelar o passado, colaborou, de maneira significativa, com a proposição de ações judiciais que responsabilizaram perpetradores de graves violações de direitos humanos, uma vez que possibilitou não apenas a instrução dos processos, mas também as investigações que fundamentavam as decisões. Por sua vez, os processos judiciais e as investigações levavam ao descobrimento de novos fatos que estimulavam, dialeticamente, o direito à verdade.

Juan Méndez (1996) explica que a categoria "verdade" da justiça de transição compreende medidas voltadas a "[...] revelar às vítimas, às suas famílias e à sociedade tudo o que possa ser estabelecido de forma confiável sobre esses eventos". O objetivo, assim, é o de estabelecer a verdade dos fatos e obter a confissão do Estado sobre as práticas criminosas de seus agentes (Teitel, 2000). Dessa forma, o direito à verdade pode ser entendido como a "necessária investigação para que as circunstâncias das graves violações de direitos humanos, ocorridas em meio a situações de violência massiva na sociedade, $[\ldots]$ possam ser esclarecidas e conhecidas, bem como os autores e vítimas de tais atrocidades" (Silva Filho, 2015, p. 51).

Jaime Malamud Goti (1998) argumenta que a transparência e a instituição de verdades por parte do próprio Estado são aspectos importantes da vida política e que precisam ser observados e garantidos em um projeto de reconstrução de uma sociedade inclusiva, quando um regime autoritário é substituído por um democrático. Ainda segundo o autor, uma transição ideal para a democracia deve ser aberta, transparente e verdadeira, e oferecer às pessoas que sofreram sob a guarda de Estados repressivos, respostas às suas muitas questões sobre a conduta do regime.

Por conseguinte, a judicialização da Operação Condor na Argentina demonstra a efetivação de uma reivindicação por justiça, por meio da atuação do Poder Judiciário, em ações voltadas à responsabilização, inclusive criminal, dos autores de graves violações de direitos humanos (Osmo, 2016, p. 24). Para Emilio Peluso N. Meyer (2016):

[...] a judicialização da justiça de transição remete à busca por implementar medidas transicionais por meio de provimentos ou decisões do Poder Judiciário. De início, é necessário considerar que estamos diante de um caminho em que se discute a legitimidade da atividade jurisdicional: com efeito, em grande número de casos, o que está envolvido nesse fenômeno é a consolidação e efetivação de direitos fundamentais e direitos humanos definidos em Constituições e normas de Direito Internacional de Direitos Humanos (Meyer, 2016, p. 106).

Assim, no que tange ao julgamento da Operação Condor, poderíamos afirmar que sua importância ultrapassa o significado da persecução penal. Além do próprio julgamento, a equalização das ações prévias e daquelas executadas durante o processo também possuem um papel no que se refere à dimensão de estabelecimento da verdade factual e na promoção da memória. Este tipo de ação permite que seja revelado e construído conhecimento, "[...] produzindo efeitos sobre a observância ou inobservância deste direito" (Osmo, 2014, p. 53).

Nos debates sobre transição política, há um tema recorrente de controvérsia no que concerne à justiça de transição, a saber, a tensão entre o binômio "verdade versus justiça" (Osmo, 2014, p. 53). Emergiu dessas discussões uma falsa compreensão acerca da relação entre justiça e verdade, como se existisse entre as duas dimensões uma contradição insanável que oporia, de um lado, a justiça 
(penal/retributiva) e, do outro lado, a história e a memória (Teitel, 2003, p. 81); impondo a escolha entre um ou outro caminho. Nesse sentido, parte da doutrina entende que "se um novo regime democrático decide confrontar o passado, surgem diversas questões adicionais. É possível, por exemplo, que ele tenha que escolher entre justiça e verdade" (TEITEL, 2003).

No entanto, divergindo do entendimento de que há um conflito insuperável entre verdade e justiça, há compreensões que argumentam e defendem que a verdade pode figurar como precursora da persecução penal. O jurista francês Louis Joinet (1997), em suas interpretações sobre "o direito de saber", destaca o acesso à verdade tanto como direito individual, quanto coletivo. O autor também menciona sobre a importância do papel das comissões não judiciais de investigação, mais conhecidas como "comissões de verdade e reconciliação" (Joinet, 1997).

As comissões da verdade, uma das possibilidades de efetivação do direito à verdade, têm por objetivo investigar, pesquisar e dar visibilidade às informações e dados que foram simplesmente esquecidos ou ocultados numa narrativa sobre o passado, que insiste em mascarar a exceção em normalidade. Tais organismos emitem recomendações ao final de seus relatórios, normalmente direcionadas aos poderes do Estado, inclusive ao Poder Judiciário, servindo, em alguns casos, conforme descrito pela pesquisadora Priscilla Hayner (2011), como insumo para abertura de processos judiciais em tribunais internacionais e domésticos. Nas palavras da autora: “[...] a relação entre comissões de verdade e persecuções criminais foi variada, mas a maioria das comissões teve toda intenção de fortalecer as persecuções” (Hayner, 2011, p. 13).

O pioneirismo da Argentina concernente à justiça de transição, muito se deu em função de, imediatamente após o fim da última ditadura no país, em 15 de dezembro de 1983, ter instaurado a primeira experiência amplamente conhecida pelo modelo de "comissões da verdade", a Comissão Nacional sobre o Desaparecimento Forçado de Pessoas (Comisión Nacional sobre la Desaparición de Personas- CONADEP). E não se tratou de uma demanda imposta, como uma espécie de revanchismo de iniciativa do novo governo, antes, foi uma demanda construída a partir da mobilização da sociedade argentina.

De acordo com Claudia Hilb (2014, p. 108), durante o curto período de nove meses, a CONADEP "colheu testemunhos sobre quase 9 mil desaparecimentos, sobre a organização dos campos de concentração e o modo operativo da política de desaparecimentos, tortura e assassinatos", materializado no relatório Nunca más. Comprovando a hipótese de Priscilla Hayner (2011), sobre a possibilidade de que as pesquisas realizadas no âmbito das comissões da verdade possam servir como material probatório para instrução de futuros julgamentos, o relatório Nunca más da Argentina foi de fundamental importância para o primeiro julgamento dos militares envolvidos com graves violações de direitos humanos, conhecida como julgamento das Juntas Militares. Tal julgamento "tomou do trabalho daquela comissão 709 casos com base nos quais abriu processos contra os nove comandantes das Forças Armadas, [...] que governaram o país sucessivamente entre 1976 e 1983" (Hilb, 2014, p. 108).

Com efeito, entre abril e dezembro de 1985, os nove membros das três primeiras Juntas Militares que governaram a Argentina durante a ditadura foram julgados pela justiça civil, pelas acusações de homicídio, privação ilegítima de liberdade, práticas de tortura e outras violações ${ }^{2}$. Para

\footnotetext{
${ }^{2}$ Em 09 de dezembro daquele ano, Jorge Rafael Videla e Emilio Eduardo Massera foram condenados à prisão perpétua; Roberto Eduardo Viola e Armando Lambruschini a 17 e oito anos de prisão, respectivamente. Os outros quatro acusados
} 
María Elena Stella (2015), o julgamento foi um "rito fundamental" para a concretização da justiça de transição no país, pelo seu ineditismo e porque se converteu no "gatilho" de uma série de novas demandas judiciais, numa dinâmica que se prolonga até a presente data (Stella, 2015); comprovando a relação dialética entre justiça e verdade. Hugo Vezzetti (2002) entende que os atos significaram um "ponto de inflexão" no qual se recontava a história da ditadura argentina e fincava-se as bases de uma nova memória para a democracia argentina (Vezzetti, 2002, p.109).

Com efeito, a criação da CONADEP e, sequencialmente, a realização do julgamento da Junta Militar na Argentina contribuíram para uma cristalização de significados sobre a interação dos mecanismos de justiça de transição. Tal entendimento se encontra em consonância com a observação de Carla Osmo (2014), a respeito da possibilidade de substituir a compreensão "verdade versus justiça" pela reivindicação "verdade e justiça". Nas palavras da autora o "[...] elemento restaurativo da busca da verdade se somaria ao direito das vítimas de recorrer a instrumentos judiciais, [...] pela percepção de uma das formas de construção do conhecimento público dos eventos passados que seria o processo penal" (Osmo, 2014, p. 30). Da mesma forma, Naomi Roht-Arriaza (2006) afirma que a verdade e a justiça não são mutuamente posições exclusivas, mas se complementam. Defende-se, assim, que a "verdade e justiça são faces de uma mesma moeda" (Roht-Arriaza, 2006).

De acordo com pesquisas realizadas por duas cientistas políticas da Universidade de Minnesota, EUA, Kathryn Sikkink e Carrie Walling (2007), a implementação de tribunais de direitos humanos na América Latina - um dos instrumentos da justiça de transição utilizado no fím dos regimes autoritários - não teve como consequência a desestabilização das democracias na região, "nem aumentam os casos de violações de direitos nos países latino-americanos que o adotaram” (Sikkink e Walling, 2007).

Destaca-se outro dado importante apresentado por Sikkink e Walling (2007) relativo ao apoio da população dos países que estiveram submetidos aos regimes autoritários e que estão passando por processos de transição: nos países em que se optou pela implantação das comissões da verdade ou dos tribunais de direitos humanos, o apoio da população à punição dos violadores desses direitos não arrefece na duração dos tribunais, tampouco restaura o poder daqueles vinculados ao regime, após o início do processo de transição, a exemplo do que ocorreu na Argentina (Sikkink e Walling, 2007, p. 434).

Seguindo esta lógica de complementariedade e de compreensão holística da justiça de transição, em que se busca evitar que se imponham limites ao conjunto de mecanismos e às diferentes abordagens para lidar com violações de direitos humanos ocorridas em um passado recente, questiona-se, aqui, a posição tímida do Estado brasileiro na efetivação de uma justiça transicional comparada ao modelo argentino.

A repressão instaurada durante os anos de regime militar, tanto na Argentina como no Brasil, organizou-se em dois níveis de normatividade, combinando métodos legais/oficiais e clandestinos/extraoficiais, paralelamente. No entanto, consideradas as distinções de extensão e intensidade entre os regimes militares do Brasil e da Argentina, sobre o primeiro acrescenta-se a esta análise indicadores que colaboram na conceituação do perfil da ditadura militar e, principalmente, sobre a estratégia de normalização das ações, mesmo aquelas clandestinas e extraoficiais. Isto é,

foram absolvidos, mas não por ausência de culpa e, sim, porque não foi possível provar os delitos imputados (Stella, 2015, p. 301-312). 
acredita-se que o exercício de institucionalização e burocratização de atividades no Brasil - busca pela aparência de normalidade consubstanciada na tese de ausência de ruptura constitucional -, assim como os obstáculos impostos por meio da censura aos meios de comunicação, influenciaram na criação de um fenômeno chamado por Irene Cardoso (2011, apud Bauer, 2011) de "inexistencialismo", quer dizer, uma realidade que nunca existiu.

Esse cenário justifica, em parte, as dificuldades encontradas na obtenção de informações precisas sobre a participação brasileira em ações clandestinas e ilegais, como a Operação Condor. Além disso, os obstáculos para acesso às informações hoje existentes influenciam no bloqueio em se ter um reconhecimento oficial da participação da ditadura militar brasileira no que concerne aos brasileiros desaparecidos no Exterior e estrangeiros no Brasil ${ }^{3}$. A investigação dos desaparecimentos forçados é emblemática dos casos nos quais se prioriza o "direito de saber" ante a dimensão da responsabilização, pois, o que se busca, em um primeiro momento, é a revelação de informações a respeito do paradeiro da vítima e onde se encontram seus restos mortais.

Arceneaux (2001) declara que as diferenças institucionais entre os regimes militares do Brasil e do Cone Sul tiveram influência no grau do controle que cada um deles teve sobre a transição e, portanto, a natureza das democracias surgidas após tal processo. Essa interpretação pode suscitar compreensões mais profundas sobre a arquitetura institucional das ditaduras militares e suas heranças políticas e culturais nas sociedades atuais. Importante ressaltar que o aparelho de Estado é questionado, aqui, não como um todo unívoco, homogêneo e transcendente, mas, sim, em seu funcionamento poroso e complexo formado por uma multiplicidade de agências, orientações, atores e práticas, conforme estudos de Mariana Franco (2015).

Enfatizamos a abordagem de que um regime político é exercido por meio de instituições e, por isso, torna-se fundamental o estudo das características e do papel exercido pelas múltiplas agências formadoras deste organograma. No que tange à análise da porosidade institucional de Estados autoritários, compreender e diferenciar os padrões de uma possível burocracia autoritária imposta, bem como as estratégias que a cercam, poderiam permitir uma compreensão mais profunda dos próprios regimes e suas transições.

Assim, inseridos em um debate mais amplo sobre justiça de transição, com dupla preocupação, a compreensão do passado e os reflexos presentes, ressalta-se a importância de compreender, analiticamente, o modus operandi de instituições que tomam parte em Estados autoritários. A partir do caso da Operação Condor como recorte metodológico, ou seja, fenômeno comum entre Brasil e Argentina e os encaminhamentos antagônicos adotados, acreditamos que um dos enigmas que ainda requer um estudo aprofundado pela historiografia política dos regimes militares, fundamentado pela justiça de transição, é aquele de se explicar se houve e como se deu o envolvimento das instituições estatais responsáveis por políticas e ações fronteiriças, ou seja, as burocracias diplomáticas. Para esta definição, partiu-se do princípio de que os Ministérios das Relações Exteriores como um todo, leiase, burocracias diplomáticas, são órgãos do Poder Executivo, responsáveis pela política externa e pelas relações internacionais de seu Estado nos planos bilateral, regional e multilateral e, portanto,

\footnotetext{
${ }^{3}$ Importante considerar que muitas das pesquisas desenvolvidas e a execução de políticas públicas (como a Comissão Nacional da Verdade - CNV) que favoreceram o esclarecimento das circunstâncias dos casos de violações de direitos humanos praticados pelo Brasil, em nível nacional ou transnacional, são fruto de reinvindicações dos familiares de mortos e desaparecidos políticos, em compasso com uma demanda histórica da sociedade brasileira.
} 
dificilmente seria isenta de informações sobre atividades, mesmo que ilegais, em níveis além das fronteiras.

Reexaminar os regimes autoritários da América do Sul, sob o ponto de vista da atuação de burocracias diplomáticas durante a Operação Condor, poderia colaborar a questionar sobre o grau de colaboração e/ou consenso dessas instituições e se elas foram usadas como instrumento legitimador de políticas autoritárias, conferindo ao regime uma aparência de normalidade e legalidade. E além dessa compreensão, poderíamos indagar sobre a intenção, por parte dos governos ditatoriais, de encapsular atividades rotineiras de instituições preexistentes em prol do interesse dos regimes, de desenvolver o aspecto da normalidade. Em consequência dessa estratégia, encontram-se obstáculos, ainda hoje, tanto no acesso às informações sobre o envolvimento das instituições, quanto a qualquer possibilidade de responsabilizar penalmente agentes que estiveram envolvidos com violações de direitos humanos.

Assim sendo, o julgamento a respeito da Operação Condor, na Argentina, finalizado em 2016, é resultado de um longo e complexo processo de disputas em defesa dos direitos humanos e da pavimentação dos mecanismos de justiça de transição no país. Em função da importância do caso e suas conexões gerenciais e territoriais com o regime militar brasileiro, nos deteremos na análise dos casos de três argentinos desaparecidos no Brasil, os quais se somaram àqueles investigados no processo finalizado no julgamento. A relevância da pesquisa é reforçada pela escassez de ação análoga ajuizada no sistema de justiça nacional e pelo fato de os agentes brasileiros não terem sido responsabilizados no processo argentino.

\section{A ausência de responsabilização de agentes estatais brasileiros frente ao desaparecimento de argentinos em território nacional}

No julgamento, a organização de direitos humanos argentina, CELS, patrocinou a defesa dos familiares de três argentinos desaparecidos no Brasil: Horacio Domingo Campiglia, Mónica Susana Pinus de Binstock e Norberto Armando Habegger. Todavia, em que pese a participação comprovada de agentes estatais do Brasil no desaparecimento dos argentinos em território brasileiro, não houve nenhuma responsabilização penal dos repressores brasileiros, seja na Argentina ou no Brasil.

No Brasil, a ausência de condenação criminal individual de agentes da ditadura que perpetraram crimes contra a humanidade tem sido fundamentada na Lei de Anistia (Lei 6.683/1979), utilizada pelos magistrados nas decisões judiciais para sustentar a interpretação de que, em razão de sua incidência, estariam anistiados os perpetradores desses crimes. Outros fundamentos seriam a prescrição e a irretroatividade da lei penal ${ }^{4}$. Nesse aspecto, destaca-se um dado importante, dentre os dezesseis países da América Latina que foram submetidos a regimes ditatoriais e, posteriormente, adotaram leis de anistia: apenas em um não foi realizado qualquer julgamento sobre as violações de

\footnotetext{
${ }^{4}$ A discussão em relação à validade da anistia para crimes contra a humanidade foi levada ao Supremo Tribunal Federal na Arguição de Descumprimento de Preceito Fundamental (ADPF) n ${ }^{\circ}$ 153, em 2010, proposta pelo Conselho Federal da Ordem dos Advogados do Brasil. Discutia-se, portanto, a recepção ou não do $\S 1^{\circ}$, do art. $n^{\circ} 1$, da Lei de Anistia, em relação à anistia dos crimes perpetrados por agentes da ditadura, como homicídio, desaparecimento forçado, lesões corporais, estupro, entre outros. Em desacordo com o Projeto Constituinte, retomado em 1988, o STF entendeu pela recepção da Lei de Anistia, reafirmando sua validade, inclusive para agentes públicos que perpetraram crimes contra a humanidade. Apesar da omissão do STF e o não cumprimento pelo Estado brasileiro da sentença condenatória da CteIDH, em 2014, foi ajuizada a ADPF n 320, proposta apresentada pelo Partido Socialismo e Liberdade (PSOL), com vistas a obter tutela jurisdicional relativa aos efeitos da Lei de Anistia.
} 
direitos humanos cometidas no passado, sendo este o Brasil (Hollanda, Batista e Boiteux, 2009, p. $60)$.

Em 2010, a Lei de Anistia foi declarada contrária à Convenção Americana de Direitos Humanos pela Corte Interamericana de Direitos Humanos (CteIDH) no caso Gomes Lund, relacionado a graves violações de direitos humanos, na ocasião da repressão estatal à Guerrilha do Araguaia (1972 e 1975). E, novamente, em julho de 2018, a CteIDH condenou o Estado brasileiro e considerou crime contra a humanidade as graves violações de direitos humanos cometidas pelo regime militar contra Vladimir Herzog e sua família (Meyer, 2012; 2015).

No que se refere à investigação e responsabilização de graves violações a direitos humanos perpetradas por agentes públicos brasileiros durante o regime autoritário, o Ministério Público Federal (MPF), para dar cumprimento à condenação no caso Gomes Lund, ajuizou 34 denúncias criminais para responsabilização individual dos agentes da ditadura. Ainda não houve condenações desses agentes e várias dessas denúncias foram rejeitadas preliminarmente com base na Lei de Anistia, prescrição e irretroatividade da lei penal (Tirado, 2018).

Cumpre-nos salientar que, em 2008, portanto, antes da sentença da CteIDH sobre o Caso Gomes Lund, os procuradores Marlon Weichert e Eugênia Gonzaga fizeram representação à área criminal do MPF do Rio de Janeiro, requerendo a instauração de Procedimentos Investigatórios Criminais (PICs) para apurar a responsabilidade criminal pelo sequestro dos argentinos Horacio Domingo Campiglia e Monica Susana Pinus de Binstock, no âmbito da Operação Condor. Entretanto, no ano seguinte, o procurador competente resistiu em aceitar a possibilidade de ajuizamento de ações penais e decidiu arquivar o pedido (Ministério Público Federal, 2009).

Nota-se que o Poder Judiciário da Argentina, no julgamento sobre a Operação Condor, condenou um cidadão uruguaio envolvido em violações de direitos humanos cometidas no nível extraterritorial. Assim, caso a Lei de Anistia do Brasil tivesse sido declarada inconstitucional quanto à tentativa de autoanistia e, claro, desde que provada a participação de cidadãos brasileiros nos eventos $^{5}$, estes também poderiam ser responsabilizados por suas ações.

Vale ressaltar que Horacio Domingo Campiglia, por possuir dupla cidadania, argentina e italiana, teve seu desaparecimento investigado e julgado pela justiça dos dois países. Na Itália, a partir do julgamento, em 24 de dezembro de 2007, foi decretada a prisão de 140 pessoas envolvidas na Operação Condor, incluindo 11 brasileiros (Almeida et al, 2009, p. 704-707) ${ }^{6}$. A justiça italiana continua responsabilizando penalmente perpetradores de direitos humanos de cidadãos ítalo-latinoamericanos, vítimas da Operação Condor. Em 2017, o Tribunal de Roma condenou à prisão perpétua oito repressores sul americanos e em julho de 2019 acontecerá o julgamento na segunda instância, em decorrência da apelação de alguns familiares de mortos e desaparecidos que discordarem de certas absolvições ${ }^{7}$.

\footnotetext{
${ }^{5}$ Como efetivamente restou comprovada pela desclassificação e envio ao governo argentino, pelo Departamento de Estado dos EUA, de uma série de documentos sobre a prisão de membros da organização Montoneros no Brasil. Tratarmos desta questão mais adiante.

${ }^{6}$ Os brasileiros que tiveram pedido de prisão decretada são: Octávio de Medeiros (ex-ministro do SNI), os generais Euclydes de Oliveira Figueiredo Filho (irmão do ex-presidente Figueiredo), Henrique Domingues e Antônio Bandeira (ex-comandante do $3^{\circ}$ Exército). Além deles, os coronéis Carlos Alberto Ponzi e Luíz Macksen de Castro, Agnello de Araújo Britto (ex-superintendente da Polícia Federal do Rio de Janeiro), Edmundo Murgel (ex-secretário de Segurança do Rio de Janeiro), general João Leivas Job (ex-secretário de Segurança do Rio Grande do Sul), Átila Rohrsetzer (exdiretor da Divisão Central de Informação) e o ex-delegado gaúcho Marco Aurélio da Silva Reis.

${ }^{7}$ Para mais informações, acesse os seguintes links:
} 
Recentemente, mesmo com os obstáculos legais ainda existentes, novas linhas de pesquisa interessadas na trama pseudolegal que configurou o fenômeno do terrorismo de Estado progrediram no sentido de ampliar a responsabilidade pela repressão além dos militares, a grupos clandestinos e esquadrões secretos. Essas concepções identificam a participação de funcionários de instituições regulares, ou seja, dos altos quadros da burocracia estatal. Essa constatação auxilia a qualificar as características do Estado terrorista, dando autoridade histórica a atores públicos diferenciados, expandindo o entendimento sobre o papel de burocracias estatais em tempos de regimes autoritários.

Assim, passam a ser consideradas as contribuições ativas e omissivas para sustentação de Estados autoritários de instituições como o Poder Judiciário, a burocracia administrativa, o sistema penitenciário, funções políticas de destaque (ministros, diplomatas, secretários de estado, etc.) e tantas outras instituições estatais que fazem parte da dinâmica cotidiana da Administração Pública. Essas instituições têm sido analisadas em estudos recentes, que questionam se a viabilidade e a manutenção da coalizão autoritária, impostas a partir dos golpes de Estado, contou, ou não, com o apoio dos agentes burocratas.

Essa compreensão vai ao encontro da explicação de Guillermo O'Donnell (1990) sobre a formulação do conceito de burocracia autoritária, que possibilita a superação de análises redutoras dos regimes de exceção, ampliando a compreensão das ditaduras latino-americanas ao expor engates estruturais e superestruturais entre a tecnoburocracia, civil e militar, do Estado (O’Donnel, 1990). Acredita-se que a maior parte dos estudos sobre autoritarismo presume que os regimes que chegam ao poder pela força não contam com a estrutura burocrática e com os agentes que a compõem, para manter o controle da sociedade ou para se legitimar.

O que se defende, aqui, com lastro no entendimento de Anthony Pereira (2010), é a existência de estratégias de manuseio e controle dos mecanismos institucionais como ferramenta legitimadora de ações autoritárias, tática utilizada por regimes militares latino-americanos em graus e proporções diferenciados e com maior ou menor sucesso (Pereira, 2010). Acredita-se que a dinâmica cotidiana da burocracia estatal de Estados autoritários caminhava em paralelo e, em alguns casos, até se sobrepunha às estruturas repressivas de natureza clandestina e/ou extraoficial.

Essa matriz interpretativa servirá de base para ampliar a compreensão sobre o panorama da repressão extraterritorial no Cone Sul, a partir de uma análise que leva em conta o papel desempenhado pelas instituições estatais regulares, sem desconsiderar a cooperação repressiva e as estruturas secretas e clandestinas dos "Estados predatórios" (McSherry, 2005). Considera-se, primeiramente, que as instituições estatais participaram de maneira comissiva e/ou omissa, dentro de seu escopo rotineiro das atividades desenvolvidas pelos Estados ditatoriais, até mesmo daquelas com caráter repressivo. No entanto, a participação e a atuação das burocracias estatais não significaram a anulação ou inexistência de ações extraoficiais e/ou clandestinas, pelo contrário, contribuíram para que estas ações repressivas se sustentassem, fossem exequíveis e, até certo ponto, se confundissem com uma ação rotineira do cotidiano burocrático.

Especificamente, quanto ao papel e a posição das burocracias diplomáticas, brasileira e argentina, sobre os casos de desaparecimento forçado de Norberto Armando Habegger, Horacio

https:/www.em.com.br/app/noticia/internacional/2017/01/17/interna_internacional,840297/italia-condena-oito-agentesda-repressao-por-plano-condor-mas-absolve.shtml e https://www.montevideo.com.uy/Noticias/Las-victimas-italianasdel-Plan-Condor-20-anos-buscando-justicia-

uc721857?fbclid=IwAR2CfMnt9mb6R_hLyBT7y8YxmZZEM5Pouye0ZqzXahE25qVJ615S3E10AM0 
Domingo Campiglia e Mónica Susana Pinus de Binstock, foram coletadas informações a partir de pesquisas em documentos encontrados em arquivos, principalmente diplomáticos, do Brasil e da Argentina.

\subsection{Três argentinos desaparecidos no Brasil no contexto da Operação Condor}

O primeiro dos três argentinos desaparecidos em território brasileiro foi Norberto Armando Habegger, integrante da organização Montoneros. Em 31 de julho de 1978, viajou do México - país em que se exilou desde o golpe militar argentino - para o Rio de Janeiro, em voo da companhia aérea PanAm. Chegou ao Brasil com identidade falsa, que trazia o nome de Héctor Esteban Cuello. Logo após desembarcar no Brasil, Habegger fez contato telefônico com companheiros de organização que estavam na Espanha e, desde então, encontra-se desaparecido.

Em depoimentos à Comissão Nacional da Verdade (CNV) e à Comissão da Verdade do Rio/2013 (CEV-RIO), no Brasil, o filho de Norberto, Andrés Habegger, testemunhou que seu pai fora preso por três soldados argentinos que "contaram com a ajuda da repressão brasileira para capturá$10 " 8$.

Concernente ao papel da burocracia diplomática argentina e movimentações em relação à Embaixada e consulados do país no Brasil, a respeito do desaparecimento de Norberto Habegger, há uma série de registros de caráter duvidoso, emitidos dias antes e logo depois do acontecido.

Segundo pesquisa realizada pelo historiador Facundo Fernández Barrio (2017), em 27 de julho de 1978, quatro dias antes da chegada de Habegger no Brasil, os consulados argentinos na cidade do Rio de Janeiro e São Paulo receberam telegrama secreto, advindo da Embaixada argentina em Brasília e assinado pelo embaixador Oscar Hector Camilión. No documento, o diplomata ordenava que a Direção-Geral de Informações (DGI) do Ministério das Relações Exteriores e Culto (MREC) da Argentina fosse atualizada o quanto antes, com uma lista "de residentes argentinos registrados en ellos debiendo en lo posible constar domicilios edad y profesion" (Arquivo Histórico da Chancelaria Argentina, 2014).

Na sequência, em 07 de agosto de 1978, uma semana depois do desaparecimento de Habegger, o MREC convocou o embaixador Camilión a se apresentar em Buenos Aires (Arquivo Histórico da Chancelaria Argentina, s.d.). Ao retornar à Brasília, Camilión cuidou dos preparativos para a chegada do subdiretor da DGI à capital federal brasileira, prevista para 21 de agosto de 1978. Camilión deu instruções secretas ao corpo consular argentino para que o funcionário fosse recebido pelos membros do serviço diplomático no aeroporto "a fin de facilitar el despacho de material técnico evitando el control del mismo por parte de las autoridades locales" (Arquivo Histórico da Chancelaria Argentina, 2014b).

Sobre as informações contidas nas comunicações da burocracia diplomática brasileira a respeito do desaparecimento de Norberto Habegger, há documentos secretos reportando o ocorrido e seus contornos. Em 22 de agosto de 1978, a Secretaria de Estado de Relações Exteriores (SERE), em Brasília, enviou telegrama-secreto-exclusivo à Embaixada brasileira em Buenos Aires, informando sobre uma edição do Jornal do Brasil que reportava que Norberto Habegger havia sido preso em território brasileiro e entregue às autoridades argentinas. O telegrama ainda descreveu o fato de que

\footnotetext{
${ }^{8}$ Depoimento de Andrés Habegger em Audiência Pública da CNV e da CEV-Rio do Brasil, em 30 de outubro de 2013. Disponível em: $<\mathrm{www}$. youtube.com/watch?v=CsFluzljU6o\&feature=youtu.be $>$.
} 
a esposa do desaparecido, Florinda Castro de Habbeger, esteve na Embaixada brasileira no México informando que julgava que Norberto teria sido "preso ou liquidado por organizações de segurança argentinas que operam clandestinamente no Brasil, ou que tenha sido detido por autoridades brasileiras" (Arquivo Histórico do Itamarati, 1978). Naquela oportunidade, Florinda Castro de Habegger informou que havia enviado uma carta ao embaixador argentino, Camilión, pedindo-lhe que intercedesse junto ao governo do Brasil para investigar o desaparecimento de seu marido. No entanto, exibiu recortes de jornais com declarações de Camilión nas quais afirmava desconhecer o jornalista argentino desaparecido e desmentia sua prisão no Brasil.

No caso de sequestro seguido de desaparecimento do argentino Norberto Habegger, é notável que sua possível repercussão midiática foi motivo de preocupação da burocracia diplomática dos dois países. Em comunicação qualificada como "secreta-exclusiva-urgentíssima", é reportado que a esposa de Norberto, na visita feita à Embaixada brasileira no México acompanhada por jornalista argentino, deixou clara sua intenção de "promover ampla campanha de imprensa contra os Governos brasileiro e argentino, se não receberem informações suficientes de Habegger".

Além disso, outro ponto de realce nessa mesma comunicação é o fato de que a burocracia diplomática brasileira deixa claras as informações coletadas sobre o desaparecimento e que a principal preocupação daquela instituição não era a busca por informações sobre o desaparecido, mas certificar-se de que o país estava, de fato, sendo usado como sítio de refúgio para pessoas vinculadas a grupos de esquerda latino-americanos. Conforme a nota:

[...] a serem verdadeiras as informações da senhora Habegger sobre a vinda de seu marido no Brasil, estariam comprovadas as suspeitas dos órgãos de informações brasileiros sobre articulações, em nosso território, de extremistas argentinos que aqui se refugiam por força do desmantelamento de suas organizações (Arquivo Histórico do Itamaraty, 1978a, s.p.).

É possível extrair da comunicação entre as burocracias diplomáticas argentina e brasileira que, além do diálogo sobre o cenário sociopolítico dos dois países, existia também a troca de informações acerca de presos políticos, desaparecidos e, mais grave, monitoramentos minuciosos sobre a vida daqueles considerados "subversivos". Isto é, acredita-se na utilização de serviços rotineiros e do modus operandi do Itamaraty a favor de certas ações e políticas do governo autoritário.

Alguns elementos ajudam a explicitar o papel dessa instituição burocrática brasileira, precipuamente responsável pelas políticas além-fronteiras, mas utilizada no monitoramento de estrangeiros no Brasil e brasileiros em outros países - os considerados "subversivos", ou seja, os "inimigos internos" -; uma ação facilitada pelos recursos e privilégios advindos de suas atividadesfim. Ainda em relação ao desaparecimento de Norberto Habegger, as comunicações continuaram após o fato consumado. Em 30 de agosto de 1978, o então embaixador brasileiro em Buenos Aires, a pedido da Secretaria de Estado de Relações Exteriores de informações sobre Habegger, envia telegrama secreto-exclusivo, com os dizeres: "De boa fonte altamente colocada, recebi ao fim da tarde de ontem, dia 29, as seguintes indicações sobre o jornalista argentino Norberto Habegger" (Arquivo Histórico do Itamaraty, 1978b). No documento, o embaixador confirma algumas informações já levantadas sobre o argentino, tais como o fato de ter sido jornalista, pertencente à organização Montoneros e ainda termina relatando que “[...] as autoridades de segurança argentinas 
estão a par das presentes alegações da mulher de Habegger, sobre o que estão em contato com as suas congêneres brasileiras" (idem).

Além de Habegger, outros dois casos integraram a ação judicial sobre a Operação Condor, finalizada em 2016, na Argentina: os desaparecimentos dos argentinos Horacio Domingo Campiglia e Mónica Susana Pinus de Binstock.

Em 11 de março de 1980, Horacio Campiglia, 30 anos, e Monica Susana Pinus, 26 anos, embarcaram em um voo regular no México com destino ao Rio de Janeiro, via Panamá e Caracas. Os argentinos viajaram, separadamente, com passaportes falsos, em nome de Jorge Piñeiro e María Cristina Aguirre de Prinssot (Almeida et al, 2009, p. 704-707). Campiglia e Mónica Pinus também integravam a organização argentina Montoneros, sendo Campiglia um de seus cinco principais líderes.

Poucos dias antes de viajar para o Brasil, seguindo a lógica de segurança dos grupos organizados contrários aos regimes militares, Mónica Pinus ligou para o marido, Edgardo Binstock, que havia chegado anteriormente ao Rio de Janeiro, para preparar como e onde seria o encontro após sua chegada no Brasil. Binstock seguiu o combinado, mas Mónica Pinus e Campiglia nunca apareceram (Larraquy, 2006, p. 188-189). Segundo testemunhas, ambos foram detidos por agentes brasileiros e argentinos assim que aterrissaram na pista do Aeroporto Internacional do Galeão no Rio de Janeiro? .

A respeito da captura dos dois argentinos no Brasil, de acordo com Marcelo Larraquy (2006), "Na pista, soldados de língua portuguesa armavam um cordão de isolamento e separavam os montoneros do resto da passagem, e tanto Pinus quanto Campiglia gritaram suas identidades e denunciaram que estavam sendo sequestrados" (Larraquy, 2006, p. 188-189).

O contraste entre as políticas de transição brasileira e argentina é notório no processo de revelação sobre o ocorrido com Mónica Pinus e Horario Campligia. Enquanto o governo argentino, apoiado por organizações da sociedade civil, solicitou ao Departamento de Estado dos Estados Unidos, a desclassificação de documentos referentes aos anos de repressão no país, o Brasil posicionou-se, sistematicamente, de maneira tímida sobre assuntos desse caráter. Em 2002, o Ministério de Justiça e Direitos Humanos da Argentina recebeu farta documentação do Departamento de Estado estadunidense sobre violações de direitos humanos ocorridas entre 1975 e 1984. Entre os documentos desclassificados, há provas efetivas do sequestro e posterior desaparecimento dos dois argentinos no Brasil (Almeida et al, 2009) ${ }^{10}$. Ainda sobre o acesso a informações, estes foram os primeiros de uma série de documentos desclassificados disponibilizados pelos Estados Unidos da América à Argentina. Em visita a capital argentina no ano de 2016 - às vésperas do aniversário de 40 anos do golpe militar - o ex-presidente estadunidense, Barack Obama, firmou um acordo extraordinário com o presidente argentino Mauricio Macri, em que cederia dos arquivos de seu país, registros militares, documentos de inteligência, telegramas e memorandos confidenciais a respeito da ditadura militar argentina (1973-1980). A partir daquele ano até abril de 2019 foram entregues

\footnotetext{
${ }^{9}$ Arquivo da CNV, 00092.000607/2014-11, Op. Cit. pp. 3-5.

${ }^{10}$ Arquivo da CNV, 00092.000607/2014-11, p. 194. Memorando enviado ao embaixador dos Estados Unidos em Buenos Aires pelo RSO da embaixada estadunidense, James J. Blystone, em 7 de abril de 1980, citado no Relatório da CNV, Volume I, Capítulo 6.
} 
remessa de documentos desclassificados ao governo argentino, a última delas, disponibilizou 40 mil documentos ${ }^{11}$.

Os desaparecimentos de Campiglia e Pinus, em março de 1980, não seriam os últimos atos de sequestro seguido de desaparecimento, de cidadãos argentinos em território brasileiro naquele ano. Com efeito, entre junho e agosto, outros quatro argentinos, também integrantes da organização Montoneros, foram vítimas de uma repressão multinacional, impulsionada pelo entendimento de que as fronteiras ideológicas se sobrepunham às fronteiras geográficas.

\section{Diferenças entre Brasil e Argentina na implantação de políticas públicas a favor do direito à verdade}

O reconhecimento da existência de distinções e certos antagonismos, entremeio ditaduras, referentes aos processos de revelação e desvendamento do caleidoscópio repressivo, principalmente em se tratando do papel de agências e instituições reconhecidas pelo alto nível técnico-burocrático, é resultado da equalização de uma soma de características das próprias ditaduras em questão e do processo de transição que se seguiu a esses regimes.

Em se tratando da importância de uma análise comparativa, mesmo que a pesquisa apresentada seja baseada em estudos de caso, considera-se as potenciais repercussões que a revelação de fatos em um dado contexto (caso argentino) pode ter sobre outro, sobretudo quando ainda carente de informações precisas sobre seu passado autoritário (caso brasileiro). Nesse sentido, cabe lembrar a afirmação de Peter Burke (2002), para quem "é apenas graças à comparação que conseguimos ver o que não está lá; em outras palavras, entender, a importância de uma ausência específica" (Burke, 2002, p. 40).

Em meio às similaridades existentes entre as ditaduras argentina e brasileira, destaca-se, conforme afirmado anteriormente, a implantação de práticas de repressão, como tortura, sequestros, morte e/ou desaparecimentos. Sobre as dessemelhanças, demarcam-se as conjunturas sociopolíticas e o maior ou menor na consecução das estratégias de implantação do terror pelos dois regimes. Essas particularidades resultam em diferentes níveis e perfis, tanto em relação à duração e intensidade da repressão, quanto no processo de revelação dos fatos a posteriori, já durante a transição (Bauer, 2011, p. 36).

Quanto às idiossincrasias das transições à democracia, ocorridas no Brasil e na Argentina, constata-se uma relação de antagonismo em relação ao fim dos regimes, mais uma vez, com grande influência na efetivação de política públicas relacionadas ao direito à verdade. Com efeito, na Argentina a transição ocorreu por meio de um colapso do regime autoritário, favorecendo à accountability - nas quais se notabiliza a responsabilização penal de perpetradores de violações (Lessa, 2009, p. 50). Nesse sentido, o primeiro governo argentino, logo após o fim do regime autoritário, foi capaz de implementar políticas públicas que viabilizassem o direito à memória, à verdade e à justiça. Entre essas medidas, destacam-se a criação da CONADEP e, no período seguinte,

\footnotetext{
11 Disponível em: https://exame.abril.com.br/mundo/eua-entregam-a-argentina-40-mil-documentos-sobre-a-ditadura/ e https:/www.elpais.com.uy/informacion/documentos-desclasificados-ee-uu-hoy-revelan-acuerdo-firmado-paises-plancondor-operar-matar-exterior.html
} 
a realização de julgamentos das três primeiras juntas militares e de oficiais e suboficiais que tiveram participação nos atos criminosos ${ }^{12}$.

Já no Brasil, a transição ocorreu por meio de negociação/consenso, consequentemente, com menor probabilidade de accountability (Lessa, 2009, p. 52). Por aqui prevaleceu a opção por uma política do esquecimento, por meio da recepção pela constituinte da Lei de Anistia - Lei n. 6.683 (28 de agosto de 1979) “[...] ocultando a verdade e interditando a memória” (Telles, 2005, p. 142). O que não significa que não tenha havido ações no sentido de construção da verdade sobre a ditadura brasileira, mas é parte das razões pelas quais a responsabilização dos agentes e a revelação pública das violações de direitos humanos sobre esse período ainda sejam tímidas e pouco eficazes, sobretudo em comparação como o caso argentino.

Dentre as políticas públicas implantadas pelo Estado brasileiro, após a redemocratização, que favoreceram o direito à verdade, podemos destacar: a criação da Comissão Especial sobre Mortos e Desaparecidos Políticos, em 1995, por meio da Lei n. 9.140/1995 ("Lei dos Desaparecidos") ${ }^{13}$. Sequencialmente, priorizou-se no Brasil uma política de reparação financeira às vítimas - como a criação da Comissão de Anistia ligada até pouco tempo ao Ministério da Justiça, com o objetivo de reparar moral e economicamente as vítimas de atos de exceção e arbítrio (Abrão e Torelly, 2013). E a criação da Comissão Nacional da Verdade (CNV), em 2011, nos termos da Lei n ${ }^{\circ} 12.528$ (Torelly, 2018).

Além de as comissões da verdade, os arquivos são outra ferramenta importante na efetivação do direito à verdade, no esclarecimento e memória de violações de direitos humanos. Acredita-se que "eles abrigam testemunhos que auxiliam no processo de reconstrução da história e ressignificam a memória e a verdade, aprofundando e consolidando a democracia” (Osmo e Santos, 2016, p. 14). O "direito de saber", como discutido por Louis Joinet (1997), aborda também o dever do Estado de preservar os arquivos relacionados às violações de direitos humanos (Osmo e Santos, 2016).

$\mathrm{Na}$ Argentina, os acervos reconhecidos como "Arquivo da repressão" englobam diversos fundos documentais produzidos tanto pelo próprio Estado - registrando suas atividades ilícitas com fins persecutório -, quanto material produzido a partir da busca de informações sobre os desaparecidos, realizada pela sociedade civil e/ou pelo Estado (pós-ditadura) (Catela, 2011). Destacase a criação de diversos tipos de instituições para albergar os fundos documentais vinculados às ações repressivas do Estado em tempos de interrupção da ordem constitucional. Entre os acervos públicos da Argentina, um que merece realce para a pesquisa ora apresentada é o projeto Unidades de Relevamiento Documental, criado por meio do Decreto 4/2010, como políticas de Estado dentro dos próprios Ministérios. Uma das iniciativas foi tomada pelo Ministério das Relações Exteriores e Culto, ao criar um buscador documental, por meio de acordo de cooperação com o CELS. O acordo de cooperação resultou na criação de uma comissão especial, em 2011, nomeada como Comisión de

\footnotetext{
${ }^{12}$ No entanto, esse processo logo seria interrompido, no ano de 1986, quando foram aprovadas, sequencialmente, as leis de Ponto Final (Lei $\mathrm{n}^{\circ} 23.492$ de 1986) e a Lei da Obediência Devida (Lei $n^{\circ} 23.521$ de 1987), que obstaculizaram a persecução penal dos envolvidos nas violações de direitos humanos durante a ditadura. Tais medidas demonstram a complexidade do processo de transição de um Estado de exceção para o Estado que respeite e salvaguarde os direitos humanos, as práticas e a aplicação dos mecanismos transicionais, que podem ser marcadas por avanços e recuos.

${ }^{13} \mathrm{O}$ processo de reunião de informações sobre os crimes praticados e o paradeiro dos desaparecidos foi iniciado pela atuação de familiares e vítimas da ditadura, havendo medidas esparsas no âmbito social durante os anos 1980, como o caso do Projeto Brasil Nunca Mais. Uma iniciativa da sociedade civil, e elaborado a partir de pesquisa feita em processos que tramitaram na Justiça Militar contra opositores da ditadura, constantes dos arquivos do Superior Tribunal Militar, publicada pela Arquidiocese de São Paulo, em 1985.
} 
Relevamiento para la Recuperación de la Memoria Histórica, desencadeando o grupo de trabalho Acesso a los Archivos Históricos de Cancillería ${ }^{14}$.

No que diz respeito à política brasileira sobre arquivos, a Lei n. 8159/1991 e seu regulamento, o Decreto 4.073/2002 criaram o Sistema Nacional de Arquivos (SINAR) para desenvolvê-la. Neste sistema, incumbe ao Arquivo Nacional a função de fazer a gestão, preservação e manutenção do acesso aos documentos produzidos e recebidos pelo Poder Executivo Federal, estando compreendidos nele os arquivos do Ministério da Marinha, e parte do Ministério das Relações Exteriores. O marco normativo mais relevante no Brasil sobre o assunto é a Lei de Acesso à Informação (Brasil, 2011).

Importante mencionar a criação, em 2009, do portal de informações conhecido como "Memórias Reveladas", administrado pelo Arquivo Nacional, tendo por objetivo disponibilizar arquivos sobre o período entre as décadas de 1960 e 1980 e sobre as lutas de resistência à ditadura militar. Apesar de considerável importância do acervo, já liberado ao público, há outros documentos que deveriam ser integrados a estes fundos e que ainda não o foram, como, por exemplo, o acervo referente às comunicações das embaixadas brasileiras durante o regime militar, atualmente sob a guarda do Arquivo Histórico do Itamaraty ${ }^{15}$.

Evidencia-se, portanto, que no caso do Brasil, não obstante as medidas descritas de centralizar essa documentação sensível em instituições arquivísticas públicas e desvinculadas dos seus órgãos originários, as Forças Armadas, as Forças Policiais e o Ministério das Relações Exteriores ainda detêm parte considerável da documentação referente ao período da ditadura militar. Sobre a questão, a CNV recomendou a realização de esforços na localização de documentos relativos à ditadura militar existentes em missões diplomáticas e repartições consulares, determinando o recolhimento desse material junto ao Arquivo Nacional. Na oportunidade, ressaltou ainda a importância da cooperação internacional na identificação de documentos referentes ao período investigado ${ }^{16}$.

14 Cf. Página on-line dos Arquivos Históricos da Chancelaria da Argentina. Disponível em: http://www.desclasificacion.cancilleria.gob.ar/. O buscador documental, disponibilizado desde 2014 via internet, com mais de 5 mil documentos, abertos à consulta pública, a respeito da burocracia diplomática do país durante os anos de ditadura militar.

${ }^{15}$ No trajeto para realização desta pesquisa, são notórias as diferenças existentes entre Brasil e Argentina no quesito "acesso aos arquivos da ditadura militar", principalmente em se tratando de instituições de alto escalão, como o caso dos Ministérios de Relações Exteriores. Contudo, na pesquisa sobre o Ministério das Relações Exteriores e Culto da Argentina foi possível ter acesso aos documentos de forma simples e direta pelo site oficial na internet. No Brasil, em relação ao Itamaraty, os documentos disponíveis no Arquivo Nacional são referentes ao SNI, da sessão Divisão de Segurança e Informação do MRE (DSI/MRE) e sobre o centro clandestino, criado em 1966, no âmbito do MRE, conhecido como Centro de Informações do Exterior (CIEX). Os demais informes e documentos retratando a comunicação entre as embaixadas durante a ditadura militar ainda estão sob o domínio do Arquivo Histórico do Itamaraty. E para ter acesso a esses documentos, faz-se necessária pesquisa em campo na capital federal, Brasília, ou na cidade do Rio do Janeiro, a depender dos anos a serem pesquisados, com agendamento e autorização prévia.

16 Ao tratar sobre o "Prosseguimento e fortalecimento da política de localização e abertura dos arquivos da ditadura militar", a CNV recomendou "que tenha prosseguimento a localização, em missões diplomáticas e repartições consulares brasileiras, da documentação relativa ao período da ditadura militar, recolhendo-se esse acervo ao Arquivo Nacional. Recomenda-se, também, a continuidade da cooperação internacional visando à identificação, em arquivos estrangeiros e de organizações internacionais, de documentação referente ao período de investigação da CNV" (Arquivo da Comissão Nacional Da Verdade, 2014, p. 975). 


\section{Conclusão}

Duas das dimensões da justiça de transição - o direito à verdade e o direito à justiça - têm uma forte tendência de retroalimentação, no sentindo que o conhecimento dos fatos pode instruir ações nas instituições judiciais, assim como novas ações podem revelar novos fatos. A busca por justiça, efetivada em parte pela atuação do Poder Judiciário nacional e/ou instâncias internacionais, e o direito à verdade, implementado por meio de instrumentos como as comissões da verdade, colocam em marcha ações de investigação e condenação de violadores de direitos humanos. O enfrentamento de violações de direitos cometidas no passado, por meio da responsabilização judicial de agentes estatais envolvidos em ações repressivas, e o fomento do direito à verdade - garantido pelas investigações de fatos, abertura e publicização de arquivos - são movimentos que, inevitavelmente, interpenetram-se, tendendo um a servir como insumo para a realização do outro.

Nos processos de justiça de transição, a compreensão sobre a importância da complementariedade entre os mecanismos justiça e verdade é revelada, com maior clareza, a partir de análises comparativas e de estudos de caso. Ao discutir o significado do julgamento ocorrido na Argentina, que resultou na responsabilização de agentes estatais envolvidos em ações repressivas transnacionais, no contexto da Operação Condor, reconheceu-se o resultado como consequência da efetivação de políticas públicas que favoreceram o acesso aos fatos, ou seja, ao direito de saber daquela sociedade. Assim, a efetivação do direito à verdade, que possibilitou o desvelamento das ações repressivas, serviu de base para a abertura do processo judicial que conduziu a concretização de parte da justiça.

Analisou-se nesse trabalho como as diferenças entre as características das ditaduras e dos processos transicionais do Brasil e da Argentina - com reflexos nas administrações após as redemocratizações desses países - influenciaram o fato de que, em um julgamento que tratou de uma operação repressiva transnacional, em que sabidamente estiveram envolvidos agentes argentinos, brasileiros e de outros países da América do Sul, nenhum brasileiro foi indiciado; mais grave, nem mesmo os casos que ocorreram em território brasileiro foram a juízo, mesmo tendo sido investigados. Essa ausência de responsabilização de agentes estatais brasileiros se dá muito em função da anistia, que ainda vigora no País, apesar de ter sido declarada inconvencional pela Corte Interamericana de Direitos Humanos.

Assim, inspirados nos três casos de argentinos desaparecidos no Brasil - Horacio Domingo Campiglia, Mónica Susana Pinus de Binstock e Norberto Armando Habegger - investigados no processo sobre a Operação Condor, no Tribunal Oral n. 1 em Buenos Aires, nos debruçamos sobre uma análise da documentação diplomática de acervos brasileiro e argentino, guiados pela compreensão ampliada da responsabilidade pela repressão ditatorial, que está além dos militares, grupos clandestinos e esquadrões secretos.

Nesses termos, foi possível observar neste trabalho, a partir de pesquisa documental que, com o fortalecimento e o encapsulamento da burocracia diplomática brasileira, promovidos pelo regime militar, pôde-se, em um primeiro momento, garantir a reprodução de práticas que beneficiavam o regime sob aparência do discurso da melhor técnica. No segundo momento, após a redemocratização, tornou-se mais dificultoso averiguar o perfil das ações dessas instituições durante a ditadura militar, uma vez que as atividades faziam parte de seu ambiente rotineiro, sobre estas não se levantaria a menor suspeita, afinal, eram ações cotidianas da burocracia institucional. 
Sendo esta uma das características da ditadura militar brasileira que a difere da ditadura argentina, a saber, a manutenção da burocracia como estratégia de legitimação da repressão imposta; uma estratégia que favoreceu não só o regime à época, mas continua auxiliando na manutenção de um véu de normalidade sobre práticas repressivas violadoras de direitos humanos, o que faz com que essas violações senão são declaradas inexistentes são justificadas como necessárias naquele contexto sócio histórico.

Por fim, ainda sob o olhar de uma compreensão ampliada sobre a responsabilização de perpetradores de direitos humanos durante ditaduras militares, é possível concluir, a partir da análise da documentação diplomática dos acervos brasileiro e argentino, que os responsáveis estão para além dos militares, dos grupos clandestinos e dos esquadrões secretos; abrangendo, na realidade, um encapsulamento da burocracia estatal a favor do autoritarismo imposto, com as particularidades inerentes a cada contexto nacional considerado.

\section{Referências}

ABRÃO, Paulo; TORELLY, Marcelo. Mutações do conceito de Anistia na Justiça de Transição Brasileira: a terceira fase da luta pela anistia. In: SILVA FILHO, José Carlos Moreira da; ABRÃO, Paulo; TORELLY, Marcelo (Orgs.). Justiça de Transição nas Américas: olhares interdisciplinares, fundamentos e padrões de efetivação. Belo Horizonte: Fórum, 2013.

ALMEIDA, Criméia; LISBOA, Suzana K.; TELES, Janaína de Almeida; TELES, Maria Amélia (Orgs). Dossiê ditadura: mortos e desaparecidos políticos no Brasil (1964-1985). São Paulo: Ieve/Imprensa Oficial, 2009.

ARCENEAUX, Craig. Bounded Missions: Military Regimes and Democratization in the Southern Cone and Brazil. University Park: Pennsylvania State University Press, 2001.

ARQUIVO da Comissão Nacional da Verdade. Relatório da Comissão Nacional da Verdade [Online]. Disponível em: http://cnv.memoriasreveladas.gov.br/. Acesso em: 18 abr. 2019.

ARQUIVO da Comissão Nacional da Verdade. Arquivo CNV, 00092.003073/2014-85: Relatório de pesquisa "A repressão além-fronteiras - A participação do Itamaraty". Disponível em:

http://cnv.memoriasreveladas.gov.br/images/documentos/Capitulo6/Nota\%2018\%2019\%2020\%202 $1 \% 2039 \% 2041 \% 2042 \% 2093 \% 20$ -

\%2000092_003073_2014_85\%20Relatorio\%20de\%20Pesquisa.pdf. Acesso em: 18 abr. 2019.

ARQUIVO Histórico da Chancelaria da Argentina. Disponível em:

http://desclasificacion.cancilleria.gov.ar/. Acesso em: 18 abr. 2019.

ARQUIVO Histórico da Chancelaria da Argentina. Telegrama diplomático secreto n. 19.

Desclassificação 747/2014. Disponível em:

http://desclasificacion.cancilleria.gov.ar/userfiles/documentos/Seleccion-Brasil/CRJ01_014.pdf.

Acesso em: 18 abr. 2019.

ARQUIVO Histórico da Chancelaria da Argentina. Resolução ministerial n. 1417.

Desclassificação: Não informada. Disponível em:

http://desclasificacion.cancilleria.gov.ar/userfiles/documentos/RESOLUCIONES_PUBLICAS/Res1

417-1978.pdf. Acesso em: 18 abr. 2019. 
ARQUIVO Histórico da Chancelaria da Argentina. Telegrama diplomático secreto n. 24. Desclassificação 747/2014b. Disponível em: http://desclasificacion.cancilleria.gov.ar/userfiles/documentos/Seleccion-Brasil/CSP01_017.pdf. Acesso em: 18 abr. 2019.

ARQUIVO Histórico da Chancelaria da Argentina. La Judicialización de la Operación Cóndor. Informe da Procuradoria de Crimes contra a Humanidade, Buenos Aires, novembro de 2015. Disponível em: http://www.fiscales.gob.ar/wp-content/uploads/2015/11/ informe-ProcuLesa-OpC\%C 3\% B3ndor-Final.pdf. Acesso em 18 abr. 2019.

ARQUIVO Histórico do Itamaraty. Pesquisa in loco, imagens dos arquivos. In: PEREIRA, Vanuza Nunes. Burocracias diplomáticas em ditaduras entrelaçadas: Brasil e Argentina. Dissertação de Mestrado. Universidade Federal de Minas Gerais, 2018.

ARQUIVO Histórico do Itamaraty. Pesquisa in loco, imagens dos arquivos. Telegrama-secretoexclusivo, n. 971. Seção de Correspondência Especial. Telegramas Secretos-Exclusivos/Retidos em Embaixadas. Ano 1978a; Caixa 11.

ARQUIVO Histórico do Itamaraty. Pesquisa in loco, imagens dos arquivos. Telegrama-secretoexclusivo, n. 2716. Seção de Correspondência Especial. Série Ultrassecreta para o Chanceler. Ano 1978b; Caixa 10.

BAUER, Caroline S. Um estudo comparativo das práticas de desaparecimento nas ditaduras civilmilitares argentina e brasileira e a elaboração de políticas de memória em ambos os países. Tese de Doutorado. Universidade Federal do Rio Grande do Sul, 2011.

BRASIL. Lei $n$. 12.527 (18 de novembro de 2011). Disponível em: http://www.planalto.gov.br/ccivil_03/ ato2011-2014/2011/lei/112527.htm. Acesso em: 18 abr. 2019.

BRASIL. Ministério Público Federal. Procuradoria da República no estado do Rio de Janeiro. Ref.: Autos $n^{\circ}$. 1.30.011.002822/2008-77. Promoção de Arquivamento, 2009.

BURKE, Peter. História e teoria social. São Paulo: UNESP, 2002.

CATELA, Ludmila da Silva. O mundo dos arquivos. In: REÁTEGUI, Felix (Ed.). Justiça de Transição: manual para a América Latina. Brasília/Nova Iorque: Comissão de Anistia, Ministério da Justiça/Centro Internacional para a Justiça de Transição, 2011.

DINGES, John. Os anos do Condor: uma década de terrorismo internacional no Cone Sul. São Paulo: Companhia das Letras, 2005.

FERNÁNDEZ BARRIO, Facundo. Diplomacia y represión extraterritorial: el Servicio Exterior argentino ante la contraofensiva de Montoneros en Brasil (1978-1980). XVI Jornadas interescuelas de Mar del Plata, 2017.

FRANCO, Mariana. Do terrorismo de Estado à violência estatal: problemas históricos e historiográficos no caso argentino. In: MOTTA, Rodrigo Patto Sá (Org.). Ditaduras Militares: Brasil, Argentina, Chile e Uruguai. Belo Horizonte: Editora UFMG, 2015.

GARZÓN REAL, Baltazar (Org). Operación Cóndor: 40 años después. Buenos Aires: Centro Internacional para la Promoción de los Derechos Humanos (CIPDH) Categoría II UNESCO, 2016.

HAYNER, Priscilla B. Unspeakable truths: transitional justice the challenge of truth commissions. New York: Routledge, 2011.

HILB, Claudia. A Virtude da Justiça e seu Preço em Verdade: uma Reflexão sobre os Julgamentos das Juntas Militares na Argentina à luz da Comissão da Verdade e Reconciliação da África do Sul. Novos Estudos Cebrap, n. 99, p. 107-118, 2014. 
HOLLANDA, Cristina Buarque de; BATISTA, Vanessa O.; BOITEUX, Luciana. Justiça de transição e direitos humanos na América Latina e na África do Sul. Revista OABRJ, v. 25, n. 5, p. 55-75, 2009.

JOINET, Louis. Comisión de Derechos Humanos. ONU, Subcomisión de Discriminación y Protección de las Minorías, 49 sesión, E/CN. 4/Sub. 2/1997/20/Rev.1. 02 de outubro de 1997.

LARRAQUY, Marcelo. Fuimos soldados: historia secreta de la contraofensiva montonera. Buenos Aires: Aguilar, 2006.

LESSA, Francesca. Justicia más allá de las fronteras: los crímenes transnacionales de Plan Cóndor. Oxford/Santiago de Chile: University of Oxford/Ministerio de Justicia y Derechos Humanos, 2016.

. Justice beyond Borders: The Operation Condor Trial and Accountability for

Transnational Crimes in South America. International Journal of Transitional Justice, v. 9, n. 3, p. 494-506, 2015.

. The missing memory of transitional justice: how Argentina and Uruguay confronted past evils, 1983-2009. Thesis. London School of Economics, 2009.

MALAMUD GOTI, Jaime. Dignity, Vengeance, and Fostering Democracy. University of Miami Inter-American Law Review, v.29, n.3, p. 417-449, 1998.

MCSHERRY, J. Patrice. Predatory States: operation condor and covert war in Latin America. Lanham: Rowman and Littlefield, 2005.

MÉNDEZ, Juan. Accountability for past abuses. The Helen Kellogg Institute for International Studies, Working Paper n. 233, sept. 1996. Disponível em:

http://kellogg.nd.edu/publications/workingpapers/WPS/233.pdf. Acesso em: 18 abr. 2019.

MEYER, Emilio Peluso Neder. Judicialização da Justiça de Transição: impactos a partir e sobre o constitucionalismo contemporâneo. In: PIOSEVAN, Flavia; PRADO SOARES, Inês Virginia (Coords). Impacto das Decisões da Corte Interamericana de Direitos Humanos na Jurisprudência do STF. Salvador: Juspodivm, 2016.

. Crimes contra a Humanidade, Justiça de Transição e Estado de Direito: Revisitando a Ditadura Brasileira. Brasiliana, v. 4, p. 208-242, 2015.

. Ditadura e responsabilização: elementos para uma justiça de transição no Brasil. Belo Horizonte: Arraes Editores, 2012.

O’DONNELL, Guillermo. Análise do autoritarismo burocrático. Rio de Janeiro: Paz e Terra, 1990.

ONU. Relatório do Secretário Geral da ONU ao Conselho de Segurança n ${ }^{\circ}$ S/2004/616, de 23 de agosto de 2004: El Estado de derecho y la justicia de transición en las sociedades que sufren o han sufrido conflictos. ONU, 2004.

OSMO, Carla. Judicialização da justiça de transição na América Latina. Brasília: Ministério da Justiça, Comissão de Anistia/Rede Latino-Americana de Justiça de Transição (RLAJT), 2016.

. Direito à verdade: origens da conceituação e suas condições teóricas de possibilidade com base em reflexões de Hannah Arendt. Tese de Doutorado. Universidade de São Paulo, 2014.

OSMO, Carla; SANTOS, Shana M. P. (Orgs). Justiça e arquivos no Brasil: perspectivas de atores da justiça de transição. Belo Horizonte: Rede Latino-Americana de Justiça de Transição (RLAJT)/ Centro de Estudos sobre Justiça de Transição, Universidade Federal de Minas Gerais (CJT/UFMG), 2016. 
PEREIRA, Anthony W. Ditadura e Repressão: o autoritarismo e o estado de direito no Brasil, no Chile e na Argentina. São Paulo: Paz e Terra, 2010.

PEREIRA, Vanuza Nunes. Burocracias diplomáticas em ditaduras entrelaçadas: Brasil e Argentina. Dissertação de Mestrado. Universidade Federal de Minas Gerais, 2018.

ROHT-ARRIAZA, Naomi. The new landscape of transitional justice. In: ROHT-ARRIAZA, Naomi; MARIEZCURRENA, Javier (Eds.). Transitional justice in the twenty-first century: beyond truth versus justice. Cambridge/New York: Cambridge University Press, 2006.

SIKKINK, Kathryn. From Pariah State to Global Protagonist: Argentina and the Struggle for International Human Rights. Latin American Politics and Society, v. 50, n. 1, p.1-29, 2008.

SIKKINK, Kathryn; WALLING, Carrie Booth. The impact of Human Rights Trials in Latin America. Journal of Peace Research, v. 44, n. 4, p. 427-445, 2007.

SILVA FILHO, José Carlos M. Justiça de Transição: da ditadura civil-militar ao debate justransicional: direito à memória e à verdade e os caminhos da reparação e da anistia do Brasil. Porto Alegre: Livraria do Advogado Editora, 2015.

STELLA, María Elena. A un cuarto de siglo, reflexiones sobre el Juicio a las Juntas Militares en Argentina. Cuadernos del Centro de Estudios de Diseño y Comunicación, ano 15, n. 52, p. 301-312, 2015.

TEITEL, Ruti. Transitional Justice Genealogy. Harvard Human Rights Journal, v. 16, p. 69-94, 2003.

. Transitional Justice. New York: Oxford University Press, 2000.

TELES, Janaína. Os herdeiros da memória. A luta dos familiares de mortos e desaparecidos políticos por verdade e justiça no Brasil. Dissertação de Mestrado. Universidade de São Paulo, 2005.

TIRADO, Felipe G. A. Human rights, transitional justice and transnational law: towards accountability for crimes against humanity in Brazil. Dissertação de Mestrado. Universidade Federal de Minas Gerais, 2018.

TORELLY, Marcelo. Assessing a late Truth Commission: challenges and achievements of the Brazilian National Truth Commission. International Journal of Transitional Justice, v. 12, n. 2, p. 194-215, 2018.

VEZZETTI, Hugo. Passado y presente. Guerra, sociedad y dictadura en la Argentina. Buenos Aires: Siglo XXI, 2002.

ZYL, Paul Van. Promovendo a justiça transicional em sociedades pós-conflitos. Revista Anistia política de justiça e transição, n. 1, p. 32-55, 2009.

Artigo recebido em: Abril/2019

Artigo aprovado em: Julho/2019 
Vanuza Nunes Pereira (nuzanunes@gmail.com) é Mestra em Direito pela Universidade Federal de Minas Gerais (UFMG).

\title{
Verdade e Justiça entre Oposição e Complementariedade: apontamentos sobre as diferenças no tratamento da Operação Condor pela Justiça de Transição no Brasil e na Argentina
}

Resumo. A partir de uma pesquisa documental abrangendo a burocracia diplomática do Brasil e da Argentina, associada a uma revisão bibliográfica sobre justiça transicional no Cone Sul, nosso objetivo é demonstrar a hipótese de complementaridade entre verdade e justiça no âmbito dos mecanismos de concretização da justiça de transição. Nosso recorte considera as atividades de agentes estatais dos regimes autoritários brasileiro e argentino no contexto da Operação Condor, bem como o seu posterior tratamento pelos Tribunais dos respectivos países, agora em ambiente democrático. Nossos resultados revelam a maior capacidade do modelo argentino no tratamento dialético do binômio verdade/justiça, em comparação com um modelo nacional ineficiente, centrado na dimensão de uma verdade opaca e ainda circunscritos por inúmeros obstáculos como a Lei de Anistia e o negacionismo.

Palavras-chave: Justiça de Transição; Verdade/Justiça; Brasil; Argentina.

\section{The Opposition and the Complement between Truth and Justice: the different decisions about Condor Operation taken by Transition Justice in Brazil and Argentina}

\begin{abstract}
Based on a documentary research covering the diplomatic bureaucracy of Brazil and Argentina, coupled with a bibliographic review on transitional justice in the Southern Cone, our goal is to demonstrate the hypothesis of complementarity between truth and justice in the context of mechanisms for the realization of transitional justice. Our review considers the activities of Brazilian and Argentine state agents of the authoritarian regimes in the context of Operation Condor, as well as their subsequent treatment by the Courts of the respective countries, now in a democratic environment. Our results reveal the greater capacity of the Argentine model in the dialectical treatment of the truth/justice binomial, compared to an inefficient national model, centered on the dimension of an opaque truth and still circumscribed by numerous obstacles such as the Amnesty Law and denialism.
\end{abstract}

Keywords: Transition Justice; Truth/Justice; Brazil; Argentina. 